Chloramphenicol has been successfully used in the treatment of bacteroides infections (Johnson, 1962; Bodner et al., 1970) and has been shown to be bactericidal to $B$. fragilis in vitro (Ingham et al., 1968) but has obvious clinical disadvantages. Large doses of benzylpenicillin have been advocated (Keusch and O'Connell, 1966; Gelb and Seligman, 1970), but the work of Ingham et al. (1968) showed that $B$. fragilis is often resistant to benzylpenicillin and ampicillin. Erythromycin is bactericidal to Bacteroides spp. in vitro (Ingham et al., 1968) and has been used successfully in the treatment of a case of bacteroides brain abscess (Ingham et al., 1970). However, rapid development of resistance to erythromycin by bacteroides has been demonstrated in vitro by Kislak (1972).

Laboratory studies have shown that the lincomycins are bactericidal to Bacteroides spp. (Ingham et al., 1968, 1970), and Kislak (1972) found that clindamycin is superior to 23 other antibiotics tested against this organism. Serious toxic effects with the lincomycins are uncommon, though diarrhoea may be a troublesome side effect of lincomycin administration (Price et al., 1968) and skin rashes may be encountered during treatment with clindamycin (Geddes et al., 1970). The lincomycins might be expected to possess further advantages in the treatment of bacteroides infections by virtue of their mechanism of action on bacterial ribosomes rather than on cell walls. Therefore it may be anticipated that they will be effective against L-forms, which are known to occur frequently in bacteroides (Dienes, 1948).

\section{References}

Bodner, S. J., Koenig, M. G. and Goodman, J. S. (1970). Annals of Internal Medicine, 73, 537 .

Cowan, S. T., and Steel, K. J. (1965). Manual for the Identification of Medical Bacteria. London, Cambridge University Press.

Dienes, I. (1948). Fournal of Bacteriology, 56, 445.

Dienes, I. (1948). Fournal of Bacteriology, 56, 445.

Finegold, S. M., and Hewitt, W. L. (1955-6). Antibiotic

Garrod, L. P. (1955). British Medical Fournal, 2, 1529. eddes, A. M., Bridgewater, F. A. J., Williams, D. N., Oon, J., and Grimshaw, G. J. (1970). British Medical fournal, 2, 703. Gelb, A. F., and Seligman, S. J. (1970). Fournal of the American Medical

Gesner, B. M., and Jenkin, C. R. (1961). Fournal of Bacteriology, 81, 595.

Gillespie, W. A., and Guy, J. (1956). Lancet, 1, 1039.

Gunn, A. A. (1956). Fournal of the Royal College of Surgeons of Edinburgh, 2, 41.

Hoogendijk, J. L. (1965). Antonie van Leeuwenhoek, 31, 383.

Ingham, H. R., Selkon, J. B. Codd, A. A., and Hale, J. H. (1968). Fournal of Clinical Pathology, 21, 432.

Ingham, H. R., Selkon, J. B., Codd, A. A., and Hale, J. H. (1970). fournal of Clinical Pathology, 23, 254.

Johnson, A. C. (1962). Canadian Medical Association fournal, 86, 72

Johnstone, F. R. C., and Cockcroft, W. H. (1968). Lancet, 1, 660 .

Keusch, G. T., and O'Connell, C. J. (1966). American fournal of the Medical Sciences, $251,428$.

Kislak, J. W. (1972). Fournal of Infectious Diseases. In press.

MacLennan, J. D. (1951). In Recent Advances in Bacteriology. Chapt. XI, 3rd edn., ed., J. H. Dible. London, Churchill.

Pearson, H. E., and Anderson, G. V. (1970). Obstetrics and Gynecology, 35, 31.

Price, D. J., O'Grady, F. W., Shooter, R. A., and Weaver, P. C. (1968). British Medical fournal, 3, 407.

Rotheram, E. B., and Schick, S. F. (1969). American fournal of Medicine, 46, 80.

Tillotson, J. R., and Lerner, A. M. (1968). Annals of Internal Medicine, 68,

Wilson, G. A., and Miles, A. A. (1964). In Topley and Wilson's Principles of Bacteriology and Immunity, 4th ed. London, Arnold.

\title{
IgG3 Levels in Patients with Chronic Membranoproliferative Glomerulonephritis
}

\author{
R. A. THOMPSON
}

British Medical fournal, 1972, 1, 282-284

\section{Summary}

In patients with membranoproliferative glomerulonephritis a higher proportion of the serum IgG was IgG3 than in normal subjects, patients with other types of renal disease, or patients with non-renal diseases. Though having a lower mean serum IgG than normal their mean serum IgG3 was raised. This tendency was more pronounced in the hypocomplementaemic patients with the disorder than in those with a normal level of serum complement.

\section{Introduction}

The classification of patients with chronic renal disease relies as much on the appearance of the renal biopsy specimen as on the clinical features. Patients with glomerulonephritis presenting with the nephrotic syndrome have been separated into groups depending on whether the renal biopsy specimen shows minimal changes on light microscopy or changes of endothelial or epithelial proliferation (or both) and thickening of the basement membrane (Blainey et al., 1960; Cameron et al., 1970; Churg et al., 1970). Some patients, particularly children, present with

Regional Immunology Laboratory, East Birmingham Hospital,

R. A. THOMPSON, M.R.C.P., M.R.C.PATH., Consultant Immunologist many of the features of acute poststreptococcal nephritis but with biopsy evidence of membrane thickening and reduplication, and these go on to a chronic course, as in the case of patients presenting with the nephrotic syndrome.

The aetiology of this condition is obscure but a proportion of such patients have a persistently low serum complement level (West et al., 1965), with a circulating factor that inactivates normal complement (Spitzer et al., 1969). This might suggest an immunological mechanism, though none has been convincingly shown. The immunoglobulin levels, especially of IgG, are generally low and tests for autoreactive antibodies generally negative.

In a study on one such patient with a circulating complement inactivator (Thompson, 1972) it was found that this activity was associated with a fraction of the serum IgG rich in IgG3, and the serum level of this subclass was raised. Of the four IgG subclasses-IgG1, IgG2, IgG3, and IgG4-IgG3 represents about $8-10 \%$ of the total IgG. It is able to fix complement but its other specific functional attributes are not known.

Raised IgG3 levels were subsequently found in other patients with this form of chronic renal disease and are reported here.

\section{Materials and Methods}

Sera from patients suffering from various forms of chronic renal disease were examined. In most cases the diagnosis had been made as a result of the combined clinical and laboratory assessment and renal biopsy. Among the patients with mixed chronic renal disease (Table I, group E) were cases of chronic pyelonephritis, renal amyloidosis, polycystic kidneys, and hypertensive 
TABLE I-Serum IgG and IgG3 Levels (Mean \pm 1 S.D.) in Groups of Patients with Chronic Renal Disease

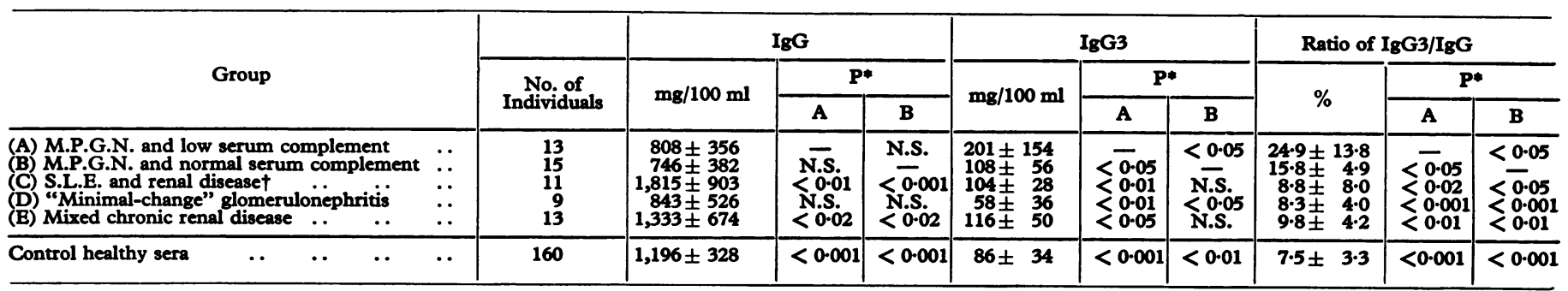

* Comparison of groups A and B with other groups.

†Eight of the sera showed a decreased complement level and three a normal level at the time of examination.

N.S. = Not significant.

M.P.G.N. Membranoproliferative glomerulonephritis.

TABLE II-Serum IgG and IgG3 Levels (Mean \pm 1 S.D.) in Groups of Patients without Renal Disease but with various other Diseases

\begin{tabular}{|c|c|c|c|c|c|c|c|}
\hline & & & & $\begin{array}{c}\text { No. of } \\
\text { Patients }\end{array}$ & IgG $(\mathrm{mg} / 100 \mathrm{ml})$ & IgG3 $(\mathrm{mg} / 100 \mathrm{ml})$ & Ratio $\frac{\text { IgG3 }}{\text { IgG }}(\%)$ \\
\hline $\begin{array}{l}\text { Recurrent respiratory infections } \ldots \\
\text { Salmonella typhi infection } \\
\text { Seropositive rheumatoid arthritis } \ldots \\
\text { Autoimmune thyroid disease }\end{array}$ & $\begin{array}{l}. \\
\because \\
\because\end{array}$ & $\ddot{n}$ & $\begin{array}{l}. . \\
\because \\
\because\end{array}$ & $\begin{array}{l}12 \\
10 \\
13 \\
11\end{array}$ & $\begin{array}{c}893 \pm 334(\mathbf{N} . S .) \\
1,648 \pm 464(\mathbf{P}<0.001) \\
1,598 \pm 516(\mathbf{P}<0.001) \\
1,528 \pm 507(\mathbf{P}<0.001)\end{array}$ & $\begin{array}{l}64 \pm 24(\mathrm{P}<0.01) \\
101 \pm 47(\mathrm{P}<0.02) \\
160 \pm 107(\mathrm{~N} . \mathrm{S} .) \\
112 \pm 41(\mathrm{P}<0.05)\end{array}$ & $\begin{array}{c}7.5 \pm 3.5(\mathrm{P}<0.001) \\
6.1 \pm 2.5(\mathrm{P}<0.001) \\
10.2 \pm 4.7(\mathrm{P}<0.01) \\
7.47 \pm 1.6(\mathrm{P}<0.001)\end{array}$ \\
\hline
\end{tabular}

Significance refers to comparison with patients with hypocomplementaemic membranoproliferative glomerulonephritis (Table I, group A).

nephropathy, as well as four cases of chronic nephritis of indeterminate aetiology which presented with non-obstructive end-stage renal failure. In addition sera were studied from other small groups of hospital patients with various disorders, including seropositive rheumatoid arthritis, autoimmune thyroid disease, and Salmonella typhi infection, and a number being investigated for recurrent respiratory infections. This last group was chosen to obtain a group of patients with comparable IgG levels to those with membranoproliferative renal disease. Control sera were from a group of $\mathbf{1 6 0}$ adult blood donors and healthy laboratory workers.

Levels of IgG and IgG3 were measured by the single radial diffusion method. Sheep anti-IgG (Fc-specific) was obtained from Dr. D. Catty, of the Department of Experimental Pathology, University of Birmingham. Anti-IgG3 was obtained by injecting a sheep with an IgG3 myeloma protein and absorbing the antiserum with a kappa and a lambda IgG1 and a kappa IgG2 myeloma protein. It was specific for the IgG3 heavy chain when tested against a panel of kappa and lambda myelomas of the IgG subclasses.

The standard serum used in the estimations was made from a pool of four normal sera. Its content of IgG was measured by using isolated normal IgG and its content of IgG3 similarly determined with four isolated IgG3 myelomas.

\section{Results}

The results of the estimations in patients with renal disease and in healthy controls are shown in Table I. Patients with hypocomplementaemic membranoproliferative glomerulonephritis had low serum IgG levels but high IgG3 levels when compared with normal subjects, patients with systemic lupus erythematosus, and, to a lesser extent, patients with other chronic renal diseases. These differences were statistically significant and in many instances were such as to be obvious on immunoelectrophoresis (see Fig.). Patients with "minimalchange" nephrotic syndrome had similar IgG levels but significantly lower IgG3 levels, and consequently percentage IgG3, when compared with hypocomplementaemic patients with membranoproliferative glomerulonephritis. Patients with membranoproliferative glomerulonephritis and a normal complement had lower IgG levels than similar patients with a low complement though the differences were not significant. The IgG3 and IgG3/IgG ratio were also lower and were just significant at the $5 \%$ level.
Comparison of the patients with hypocomplementaemic membranoproliferative glomerulonephritis with other patients suffering from non-renal conditions showed a highly significant difference in each case in the proportion of IgG that was IgG3 (Table II). The patients with typhoid, rheumatoid arthritis, and autoimmune thyroid disease had significantly higher IgG levels and, with the exception of those with rheumatoid arthritis, significantly lower IgG3 levels. The patients with recurrent respiratory infections had comparable levels of IgG but lower levels, and consequently lower percentage levels, of IgG3.

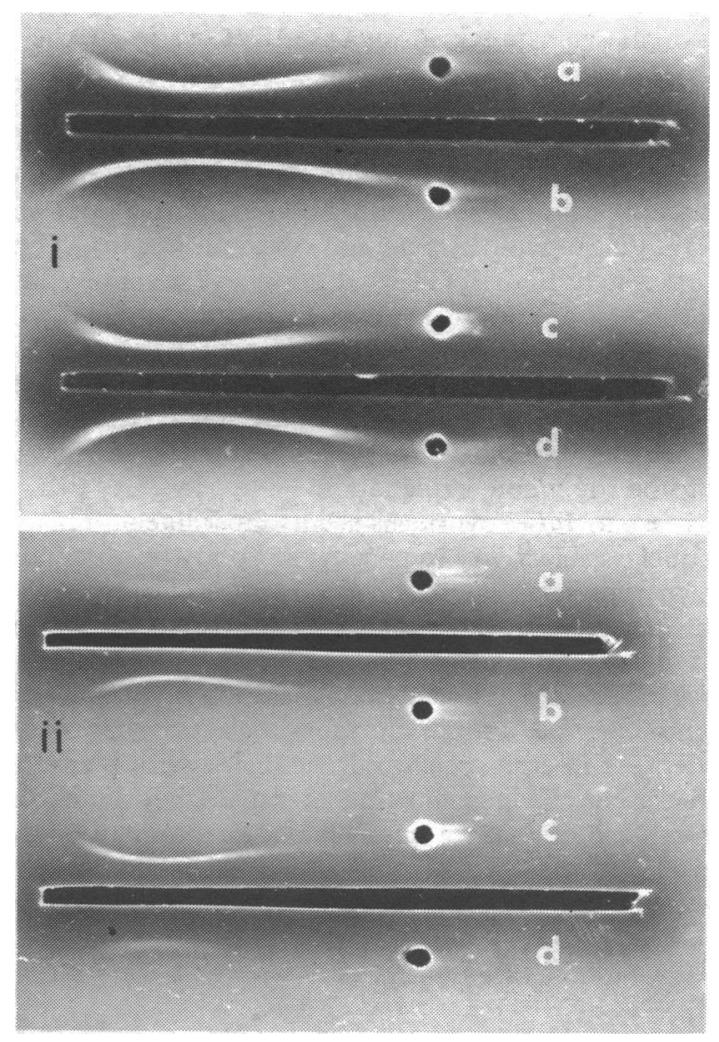

Immunoelectrophoresis of sera from (a) a patient with chronic pyelonephritis, $(b, c)$ two patients with hypocomplementaemic membranoproliferative glomerulonephritis, and (d) a healthy individual. After electrophoresis the troughs were filled with either (i) antihuman IgG-Fc, or (ii) antihuman IgG3. The anode was to the right. 


\section{Discussion}

The aetiology of membranoproliferative glomerulonephritis is obscure but it represents a common cause of chronic renal failure. Immunological mechanisms have been suspected since in many patients with normal complement, and in many with a low complement, fluorescence microscopy of renal biopsy specimens has shown $\mathrm{C} 3$ and to a less extent IgG bound in the glomerulus (Herdman et al., 1970).

The findings reported here have shown that while such patients have a low serum IgG level they have a high IgG3 level, and consequently a disproportionate amount of the serum IgG is IgG3. Examination of the families of two patients has shown that one parent (the mother in each case) had a high IgG3 level with an increased IgG3/IgG ratio, though the levels in the other siblings of the two families were normal.

It has not been possible to study enough patients with acute poststreptococcal glomerulonephritis in whom the diagnosis has been established with confidence. Nine patients with a suggestive clinical picture were studied. In four of these, all of whom had concurrent low serum haemolytic complement and $\mathrm{C} 3$ levels, the IgG3 level and ratio of $\mathrm{IgG} 3 / \mathrm{IgG}$ was raised. Three of these four had biopsy evidence of acute nephritis. In the other five patients the serum complement was normal at the time of admission and remained so on subsequent testing; biopsy confirmation of the diagnosis was available in only one of these cases. The IgG3 level and the percentage IgG3/IgG were raised in one and normal in the other four.

The high level of IgG3 in patients with chronic membranoproliferative glomerulonephritis in association with a generally low level of IgG is surprising in view of the reported increased catabolic rate and shorter half-life of this subclass. Spiegelberg et al. (1968) reported the half-life of IgG3 as 7.2 days, compared with from 10.9 to 12.4 days for the other IgG subclasses in a group of patients with neoplastic disease, and Morell et al. (1970) reported the half-life of IgG3 as 7.1 days, as opposed to 21 days for the other subclasses.

Examination of the urinary clearance of IgG and IgG3 in some of the patients is being undertaken but preliminary results so far have shown a much lower IgG3/IgG ratio in the urine than in the serum in each case. IgG3 is not known to have a different molecular weight from the other IgG subclasses, but comparison of the elution pattern on Sephadex G200 and the behaviour in the ultracentrifuge suggest that it may be of a different shape, having a slower diffusion coefficient but a smaller $S$ value (D. R. Stanworth, personal communication). Thus the disproportionately high IgG3 level may have a simple physicochemical basis due to differential retention of IgG3 with a differential decrease in its catabolism. But since the serum levels of IgA and IgM (other large immunoglobulin molecules, differentially retained by a leaky glomerulus) are not raised in patients with membranoproliferative glomerulonephritis, this would be unlikely to be the whole explanation.

An increase in IgG3 synthesis seems most likely. This would allow a subclass selectivity in specific antibody production since it is known that antibodies to certain types of antigen in man tend to be of one particular subclass (Yount, et al., 1968) though no selectivity of response is known with respect to IgG3.

Lewis et al. (1970), in a study of renal biopsy specimens using immunofluorescence, found all the subclasses represented to varying degrees in cases of chronic nephritis with membranous and proliferative changes showing granular deposits of IgG in the glomeruli, though in a case of lobular glomerulonephritis there were heavy deposits of IgG3 alone. IgG3 was not detected in those biopsy specimens showing a linear deposit of IgG in the glomeruli-that is, those suggesting anti-basement-membrane antibodies-nor to any extent in patients with lupus nephritis.

IgG3 is known to be unstable in that cryoprecipitates and aggregates form at lower levels of IgG in myeloma patients with an IgG3 myeloma than in patients with myelomas of other subclasses (Capra and Kunkel, 1970).

As has been reported (Thompson, 1972) C3 converting activity has been found associated with an IgG3-rich fraction of the IgG from a patient with membranoproliferative glomerulonephritis, and this finding has since been repeated in two other patients with hypocomplementaemic membranoproliferative glomerulonephritis and a circulating C3 inactivator. Analysis in vitro showed that the inactivation of the $C 3$ in normal serum was achieved without appreciably affecting functions associated with the early complement components $\mathrm{C1}, \mathrm{C} 4$, and C2. This, together with the observations of normal levels of these early complement components in patients with glomerulonephritis and decreased C3 levels (Gewurz et al., 1968; Kohler and Ten Bensel, 1969), suggests that C3 may be activated in patients by a mechanism other than the conventional pathway. Such an alternate pathway has been described (Götze and Müller-Eberhard, 1971).

Thus the persistence of the renal damage in such patients may be due to the formation of particular types of antigen/ antibody complex because of a high IgG3 response. Alternatively the leakage of blood with a high IgG3 content through a damaged glomerulus may cause further alteration and instability of the IgG3 molecules, possibly resulting in "non-specific" activation of complement with relatively inefficient fluid-phase complement-mediated damage. The causes of the chronicity of the disease may therefore not be related to the cause of the initial damage.

Whatever the true case further investigation of the role of IgG3 in such patients is indicated.

I am grateful to Professor J. Hardwicke and Dr. B. H. B. Robinson, of the East Birmingham Hospital, and also to other physicians in the Birmingham region for allowing me to study patients under their care. I should also like to thank Dr. D. K. Peters, of the Hammersmith Hospital, London, for sending me the sera from nine patients with membranoproliferative glomerulonephritis. I am also grateful to Miss $M$. Wall, statistician to the Birmingham Regional Hospital Board, for carrying out the statistical analyses.

\section{References}

Blainey, J. D., Brewer, D. B., Hardwicke, J., and Soothill, J. F. (1960). Quarterly Fournal of Medicine, 29, 235.

Cameron, J. S., Glasgow, E. F., Ogg, C. S., and White, R. H. R. (1970). British Medical fournal, 4, 7.

Capra, J. D., and Kunkel, H. G. (1970). fournal of Clinical Investigation, 49,610 .

Churg, J., Habib, R., and White, R. H. R. (1970). Lancet, 1, 1299.

Gewurz, H., Pickering, R. J., Mergenhagen, S. E., and Good, R. A. (1968). International Archives of Allergy, 34, 556 .

Grtze, O., and Muller-Eberhard, H. J. (1971). Fournal of Experimental Medicine, 134, $90 \mathrm{~S}$.

Herdman, R. C., et al. (1970). Medicine, 49, 207.

Kohler, P. F., and Ten Bensel, R. (1969). Clinical and Experimental Immun-

ology, 4, 191.
Lewis, E. J., Busch, G. J., and Schur, P. H. (1970). fournal of Clinical Morell, A., Terry, W. D., and Waldmann, T. A. (1970). Fournal of Clinical Investigation, 49, 673 .

Spiegelberg, H. L., Fishkin, B. G., and Grey, H. M. (1968). Fournal of Clinical Investigation, 47, 2323.

Spitzer, R. E., et al. (1969). Science, 164, 436.

Thompson, R. A. (1972). Immunology, 22, 147.

West, C. D., McAdams, A. J., McConville, J. M., Da

Yount, W. J., Dorner, M. M., Kunkel, H. G., and Kabat, E. A. (1968). fournal of Experimental Medicine, 127, 633. 